\title{
Analisis Isra'iliyyat Dalam Tafsir Hasyiah Al-Sawi Karya Ahmad Bin Muhammad Sawi Al-Maliki
}

\author{
Lumngatul Ma'arif ${ }^{1}$, Eka Prasetiawati $^{2}$ \\ ${ }^{1}$ Pascasarjana IAT UIN Raden Intan Lampung, ${ }^{2}$ IAIMNU Metro Lampung \\ 1'lumngatulmaarif22@gmail.com, ${ }^{2}$ prasetyaeka41@gmail.com
}

DOI: $10.29240 /$ alquds.v4i1.1374

Submitted: 2020-02-03 | Revised: 2020-03-19|Accepted: 2020-04-13

\begin{abstract}
This paper examines the view of Imam Sawi towards isra'iliyyat in the interpretation of the mustyiah mustard. The inclusion of isra'iliyyat in Islam began in the era of the Prophet, but that period was still counted by the Prophet. After he died, the entry of Israel became increasingly out of control. In the tabi'in era and later generations, many commentators have included isra'iliyyat in their interpretations even today. The method in this research is descriptive-analytical with content analysis for data analysis. In this study, 12 stories which are categorized as isra'iliyyat are displayed. From this research,Sawi's view of isra'iliyyatcould be analyzed.At some point,he gives comments, and he is also silent to some extent. Of the 12 stories that are displayed, there are 3 stories that get comments while the rest is without comments. Those who received comments were the story of Joseph and Zulaikha, the son of Ibrahim who was slain and the story of Zainab bint Jahsyi. From these results, it can be concluded that Sawi is a productive and critical writer, while the israiliyyat shown may be ibrah. As for not commenting, because of the nature of tawadh' he was a great Sufi from the Tariqah Khalwatiyah.
\end{abstract}

Keywords: Isra'iliyyat, Hasyiah Sawi, Ahmad Sawi’s Perspective

\begin{abstract}
Abstrak.Tulisan ini mengkaji pandangan imam Sawi terhadap isra'iliyyat dalam tafsirnya, yaitu hasyiah sawi. Masuknya isra'iliyyat dalam Islam sudah dimulai sejak zaman Nabi.Namun, masa itu masih dicounter oleh Nabi.Pasca beliau wafat masuknya israiliyat semakin tidak terkendali. Di era tabi'in dan generasi sesudahnya banyak mufassirmemasukkan isra'iliyyat dalam tafsirnya bahkan sampai sekarang, dan hal itu sepertinya sudah menjadi kelaziman sehingga perlu kehati- hatian dalam menggunakannya. Metode dalam penelitian ini bersifat deskriptif-analitis dengan analisa data content analysis. Dalam penelitian ini, ditampilkan 12 kisah yang termasuk kategori isra'iliyyat, kemudian menganalisa secara deskriptif dan menyimpulkan hasil penelitian. Dari penelitian ini bisa dianalisa pandangan Sawi terhadap isra'iliyyat, adakalanya beliau memberi komentar dan ada pula yang mendiamkan.Dari 12 kisah yang ditampilkan, terdapat 3 kisah yang mendapat komentar sedangkan sisanya tanpa ada komentar.Yang mendapat komentar yaitu kisah Yusuf dan Zulaikha, putra Ibrahim yang disembelih dan
\end{abstract}


kisah Zainab binti Jahsyi. Dari hasil ini bisa disimpulkan bahwasanya Sawi penulis yang produktif dan kritis, sedangkan israiliyyat yang ditampilkan boleh jadi sebagai ibrah. Adapun tidak memberi komentar, karena sifat tawadhu' beliau sebagai seorang sufi besar dari thariqah khalwatiyah dan juga sebagai manifestasi beliau sebagai pensyarah/penjabar dari kitab tafsir jalalain.

Kata Kunci: Isra’iliyyat, Hasyiah Sawi, Perspektif Ahmad Sawi

\section{Pendahuluan}

Tema isra'iliyyat dalam penafsiran al-Qur'an masih sangat urgen dibahas, dikarenakan terdapat sekolompok mufassir ketika mengutip isra'iliyyat tidak membedakan mana riwayat yang sahih dan mana yang dha'if. Terkadang mereka memasukkan riwayat isra'iliyyat yang berlebihan (di luar jangkauan akal manusia) khususnya yang berkaitan dengan ayat kisah tanpa mempedulikan dampak negatif yang ditimbulkan. Terjadi polemik isra'iliyyat dikalangan para ulama ada yang melarang keras, membolehkan dalam artian tidak membenarkan atau mendustakannya serta mendiskusikan apakah riwayat tersebut sesuai syari'at Islam.

Al-Qur'an merupakan kitab yang ayat-ayatnya bersifat yabtamil wujuh alma'na, memungkinkan banyak makna (penafsiran). Hal ini kemudian menimbulkan keanekaragaman pemahaman (multitafsir) yang tidak jarang menimbulkan penafsiran yang menyimpang atau salah tafsir. Terdapat banyak faktor yang menyebabkan salah dalam penafsiran, diantaranya adalah faktorketerbatasan kemampuan akal manusia dan subjektifitas seorang mufasir. Di samping itu, sikap mufasir yang kurang berhati-hati dalam mencantumkan riwayat dan tidak selektif dalam menerima sumber-sumber dari luar Islam. ${ }^{1}$ Kesalahan tafsir di sini adalah menyimpang dari jalan yang lurus, berpaling dari metode yang benar, jauh dari pokok-pokok yang benar dan sumber-sumber asli yang memiliki ketetapan dalam tafsir, melakukan kesalahan dalam penafsiran yang bertentangan dengan hakikatkebenaran, baik secara sengaja atau lalai serta tidak ada ketetapan harus merujuknya. ${ }^{2}$

Dalam sejarah perkembangan tafsir terdapat tiga bentuk penafsiran yaitu tafsir bil ma'tsur (bil-manqul), tafsir bil-ra'yi (bil-ma'qul) dan tafsir bil-isyari. Para sahabat dalam menafsirkan al-Qur'an banyak menggunakan metode bil ma'tsur sebab kehati-hatian mereka dalam menjelaskan al-Qur'an. Namun sejalan dengan perkembangan zaman bertambah besar pula porsi peranan akal dalam menafsirkan ayat al-Qur'an sehingga muncul berbagai kitab tafsir yang beraneka

${ }^{1}$ Maryam Shofa, “Ad-Dakhil Dalam Tafsir Al-Jami' Li Ahkam Al-Qur'an Karya alQurtubī: Analisis Tafsir Surah al-Baqarah,” Jurnal Subuf, Vol. 6No. 2 (2013): 271.

2Tahir Mahmud Muhammad Ya'qub, Asbab Al-Khata' Fi al-Tafsir (Riyad, Arab Saudi: Dar Ibn al-Jauzīi, 1425), 44. 
ragam coraknya. Muhammad Arkoun menyatakan bahwa al-Qur'an mempunyai kemungkinan arti yang tak terbatas dan ayat selalu terbuka untuk interpretasi baru. $^{3}$

Menurut Al-Dzahabi dalam memahami kitabullah, kalangan tabi'in mengambil riwayat berpegang pada al-Qur'an, hadits, qaul sababi, keterangan ahli kitab baik Yahudi maupun Nasrani yang bersumber dari isi kitab mereka. ${ }^{4}$ Metode yang dipakai para tabi'in sama dengan yang dipakai para sahabat, hanya saja mereka sudah mulai memasukkan isra'iliyyat dan terlebih ketika itu banyak terjadi pemutusan sanad serta pemalsuan hadits sehingga ketika membaca riwayat isra'iliyyat ${ }^{56}$ kita mesti cermat dan kritis.

Masuknya isra'iliyyat dalam Islam memang tidak dapat dihindari dari pembauran masyarakat Islam dengan ahli kitab di sekitar jazirah Arab. Sebenarnya para sahabat tidak mengambil berita dari ahli kitab dalam penafsiran kecuali sedikit. Namun seiring berjalannya waktu,di era tabi'in dan sesudahnya banyak yang mengutip berita dari mereka. Para mufasir tidak mengoreksi lebih dahulu kutipan cerita isra'iliyyat yang mereka ambil, padahal diantaranya terdapat yang tidak benar dan batil. Karena itu orang yang membaca tafsir mereka hendaknya meninggalkan yang tidak berguna dan tidak mengutip riwayat kecuali telah terbukti kesahihannya dan kebenaran ceritanya. ${ }^{7}$

Persoalan isra'iliyyat menjadi isu penting bagi kalangan mufasir modern. Sebab isra'iliyyat tidak hanya berkaitan dengan aspek teologis yang mengklaim sebagai agama sempurna sehingga tidak perlu lagi merujuk pada keterangan Yahudi dan Nasrani, al-Qur'an pun menyatakan bahwa kedua kelompok tersebut telah melakukan penyimpangan yakni isra'iliyyat berisi khurafat yang

${ }^{3}$ Muhammad Quraish Shihab, Membumikan Al-Qur'an; Fungsi Dan Peran Wabyu Dalam Kebidupan Masyarakat, (Bandung: Mizan, 1998), 54. 1976), 99.

${ }^{4}$ M. Husain Al-Dzahabi, Tafsir Wa Al-Mufassirun, vol. 1, (Beirut, Libanon: Darul Fikr,

"Isra'iliyat berasal dari bahasa Ibrani dari akar kata isra' yang berarti "hamba" dan El yang berarti "Tuhan", jadi Israel berarti hamba Tuhan. Istilah israilliyat yaitu kisah atau kejadian yang diriwayatkan dari sumber-sumber isra'il. Isra'illiyat dinisbahkan kepada 12 orang putera keturunan Nabi Ya'qub ibn Ishaq ibn Ibrahim As. yang kemudian disebut bani isra'il. Menurut M. Husain al-Dzahabi, sekalipun menunjukkan kepada kisah atau kejadian yang berasal dari sumber-sumber Yahudi, ulama tafsir dan hadits mempergunakan istilah tersebut untuk cakupan yang lebih luas. Menurut mereka, Isra'illiyat adalah segala dongengan klasik yang dinisbahkan asal riwayatnya kepada sumber-sumber Yahudi, Nasrani dan yang lainnya. Termasuk cerita-cerita yang tidak berdasar dan tidak jelas sumbernya yang sengaja dibuat oleh musuh-musuh Islam untuk mengacaukan ajaran Islam.

${ }^{6}$ M.Husain Al-Dzahabi, Al-Israilliyat Fi al-Tafsir Wa al-Hadits, 3ed. (Kairo: Maktabah Wahbah, 1986), 13.

${ }^{7}$ Manna' Khalil Al-Qattan, Studi Ilmu Al-Qur'an (Pustaka Litera Antarnusa, 2016), 499. 
merusak akidah umat Islam. Menyadari bahaya yang ditimbulkan, Muhammad Abduh sangat gencar mengkritik ulama tafsir generasi awal yang menggunakan isra'iliyyat sebagai penjelas al-Qur'an alasannya kebiasaan itu dapat mendistorsi pemahaman terhadap Islam. Sikap keras juga diperlihatkan Rasyid Ridha, ia mengatakan riwayat isra'iliyyat yang secara ekstrim diriwayatkan para ulama tafsir sebenarnya telah keluar dari konteks al-Qur'an. Bahkan Muhammad Syaltut menambahkan isra'iliyyat menghalangi umat Islam menemukan petunjukpetunjuk al-Qur'an. ${ }^{8}$

Isra'iliyyat merupakan suatu alat dalam menafsirkan al-Qur'an bagi sebagian mufasir salaf yang menjadi perhatian bagi peminat studi Islam baik muslim maupun non-muslim (orientalis). Dalam menyikapi isra'iliyyat, J.J. Jansen menyatakan mayoritas kaum muslim modernis menolak tradisi memalsukan cerita isra'iliyyat ke dalam penafsiran sebab dianggap tidak rasional, janggal dan mengandung unsur khayali semata. ${ }^{9}$

Kitab Hasyiyah al-Sawi 'Ala Tafsir Jalalain karya Syaikh Ahmad bin Muhammad Al-Sawi al-Maliki merupakan salah satu tafsir klasik dalam khazanah tafsir yang perlu dikaji untuk mengetahui sejauh mana keseriusan umat Islam dalam mengkaji al-Qur'an yang diyakini shalih likulli zaman wa makan. Tafsir darikalanganAsy'ariyahinisangatpentingdikajidalamrangkamemperkuatpahamAs wajadenganmenampilkan, mengenalkan dan menyampaikan karya intelektual ulama kepada masyarakat.

Kepopuleran Tafsir Jalalain berkembang di masyarakat Indonesia khususnya pondok pesantren dari waktu ke waktu mulai pulau Jawa seperti Lirboyo, Ploso, Sarang, Tebuireng hingga pulau Sumatra. Karena tingginya nilai tafsir Jalalain di mata para pembaca maka mengakaji tafsir ini hukumya wajib di kalangan pesantren. Selain dikenal dengan bahasa yang mudah dipahami karena bercorak lughawi, tafsir ini juga dikarang oleh ulama kenamaan yaitu Jalaludin alMahali dan Jalaludin al-Suyuti. Kepopuleran tafsir Jalalain menstimulus para ulama selanjutnya untuk membuat syarah. Namun sangat disayangkan hanya sedikit orang yang mengetahui syarah kitab Jalalain. 'Adil Nuwaihid menyatakan bahwa Hasyiyah Jamal merupakan kitab syarah dari tafsir Jalalain yang paling mashur di dunia, ${ }^{10}$ Dari sederet kitab yang dikaji di pesantren salaf di Indonesia, yang mashur dikaji adalah kitab Hasyiyah al-Sawi meskipun banyak kalangan tidak mengetahui apalagi mengenalnya.

${ }^{8}$ Muhammad Syaltut, Fatwa-Fatwa Terj. Busamin A. Ghani, vol. 1 (Jakarta: Bulan Bintang, 1977), 95.

9J.J Jansen, The Interpretation of The Koran in Modern Egypt (Leiden: E.J. Brill, 1984), 27.

${ }_{10}$ Adil Nuwaihid, Mu'jam al-Mufassirin min Sadr al-Islam Hatta Al-'Asri al-Hadir, 2 ed., vol. 1 (Libanon: Muasasah Nuwaihid al-Tsaqafiyah li al-Ta’lif wa al-Tarmah wa al-Nasyr, 1986), 218. 
Ahmad bin Muhammad Sawi termasuk ulama Sunni yang berfaham Asy'ariyah dan bermazhab Maliki. Ia dikenal sebagai ulama yang terkemuka di masyarakat di bidang tasawuf, fiqh, qira'at dan bahasa yang menghasilkan sebuah karya monumental dengan orientasi (ittijah) al-ra'yi dengan kajian yang sangat mendalam dan lengkap mencakup aspek kebahasaan, gramatika, qoul-qoul (pendapat) rajih dan juga banyak memuat riwayat-riwayat isra'iliyyat yaitu Hasyiah Al-Sawi 'Ala Tafsir Jalalain. ${ }^{11}$

Tafsir ini menarik untuk diteliti pertama, al-Sawi merupakan tafsir bercorak esoterik ${ }^{12}$ banyak menyingkap cerita-cerita luar biasa diluar jangkauan akal manusia. Hal ini tidak terlepas dari pendapat beliau yang memasukkan riwayat isra'iliyyat sebagai konsekuensi kitab syarah (basyiyah. Kedua, tafsir ini hanya di kaji di kalangan pesantren di Indonesia sehingga masyarakat umumnya tidak banyak mengetahui. Tafsir ini tergolong cukup langka, hampir tidak ditemukan tulisan-tulisan yang membahas kitab ini. Ketiga, penulis menemukan dalam tafsir al-Sawi banyak dikemukakan riwayat-riwayat isra'iliyyat, oleh karena itu penulis tertarik untuk mengetahui sikap beliau terhadap riwayat ini, menolak atau tawaquf (mendiamkan).

Penelitian ini dikategorikan dalam penelitian kepustakaan (Library Research). Objek utama kajian ini adalah kitab Tafsir Hasyiah Sawi 'Ala Tafsir Jalalain karya Ahmad bin Muhammad Sawi Al-Malikiyang berjumlah 4 jilid terbitan Dar Kutub Ilmiyah Beirut. Tulisan ini bersifat deskriptif-analitik guna melacak dan menelaah kisah isra'iliyyat dalam tafsir al-Sawi.

Kajian Tafsir Hasyiah Sawi 'Ala Tafsir Jalalain termasuk hal baru. Adapun isra'iliyyat sudah ada yang membahas diantaranya:1)Isra'iliyyat wal Maudbu'at fi Kutub al-Tafsir karya Muhammad ibn Muhammad Abu Syahbah memaparkan tentang fenomena isra'iliyyat dan hadits-hadits palsu dalam kitab tafsir. Beliau menginventarisir sebanyak 32 riwayat isra'iliyyat yang bermasalah. Selain beberapa riwayat tentang asbab an-Nuzul dan juga tentang fenomena alam; ${ }^{13} 2$ ) Isra'iliyyat Fi al-Tafsir wa al-Hadits karya Muhammad Husain al-Dzahabi menjelaskan transformasi isra'iliyyat pada tafsir hadits, macam-macamnya pada kitab tafsir hadits, sumber isra'iliyyat dan bagaimana sikap seorang mufassir menyikapinya; 3) Israiliyyat dalam Tafsir Mahasin Al-Ta'wil Karya Jamaluddin Al Qasimi, ditulis oleh Rega Hadi Yusron Skripsi UIN Sunan Ampel Surabaya

\footnotetext{
${ }^{11}$ Ahmad Muhammad Sawi al-Maliki, Hasyiah Al-Sawi 'Ala Tafsir Jalalain, vol. 1 (Beirut, Libanon: Darul Fikr, 1993), 7.

${ }^{12} \mathrm{Abdul}$ Mun'im Al-Khafi, Al-Mausu'ah al-Falsafiyyah (Beirut, Libanon: Dar ibnu Zaidan, tt), 88 .

${ }^{13}$ Muhammad Abu Syahbah, Al-Israilliyat Dan Hadits-Hadits Palsu Tafsir al-Qur'an, Terj. Mujabidin Mubayan Dkk, 2 ed. (Depok: Keira Publising, 2016), 155.
} 
2018. Penelitian ini memfokuskan masalah bentuk-bentuk isra'iliyyat dalam tafsir Mahasin Ta'wil serta pandangan Al-Qasimi terhadap isra'iliyyat dalam tafsirnya; 4) Isra'illiyat dan Maudhu'at dalam Tafsir Al-Qur'an; (Studi Tafsir al-Jalalain) karya A. Malik Madani, Disertasi UIN Sunan Kalijaga Yogyakarta 2010. Penelitian ini memfokuskan pada israiliyyat yang di anggap bermasalah dalam tafsir Jalalain menurut sebagian ulama yaitu dalam kajian desertasi A. Malik Madani Israilliyat dan Maudhu'at dalam Tafsir Al-Qur'an; (Studi Tafsir al-Jalalain), fokus kajiannya ada 12 riwayat israiliyyat yakni berkaitan dengan kisah nabi terdahulu sebanyak 7 riwayat, nabi Muhammad ada 2 riwayat, dan di luar kisah para Nabi terdapat 3 riwayat.

\section{Profil Singkat Imam Ahmad Sawi al-Maliki}

Menurut catatan sejarah, perkembangan kekuasaan dinasti Mamluk mencapai puncak kejayaannya pada tahun $1769 \mathrm{M}$ di bawah kepemimpinan Ali Bey. Philips menjelaskan nama mamluk (yang dikuasai) merupakan dinasti para budak yang berasal dari berbagai suku dan bangsa yang kemudian menciptakan satu tatanan oligarki militer di wilayah asing. Para sultan budak ini menegaskan kekuasaan mereka atas wilayah Suriah, Mesir yang sebelumnya dikuasai tentara Salib. Fondasi kekuasaan Mamluk dipelopori oleh Syajar al-Dur, janda al-Salih (w. $1249 \mathrm{M}$ ) dari dinasti Ayyubiyah yang tadinya merupakan seorang budak dari Turki (Armenia). ${ }^{14}$

Pada masa ini lahirlah pengarang tafsir Hasyiyah Sawi. Ia bernama Ahmad bin Muhammad al-Sawi al-Misri al-Khalwati. Al-Sawi lahir di Sa' al-Hijr, sebuah desa di pinggiran Mesir pada tahun $1175 \mathrm{H} / 1761 \mathrm{M}$ dan beliau wafat di Madinah al-Munawarah pada tahun 1241 H/1825 M. ${ }^{15}$ Syaikh al-Sawi merupakan seorang pemimpin ulama al-Azhar yang bermadhab Maliki dan juga menganut ajaran sufi aliran khalwatiyyah dan beliau termasuk ulama tafsir dari golongan Ahl Sunnah wa al-Jama'ah yang terkemuka di zamannya. Gurunya di bidang tarekat ialah Syaikh al-Dardiri yang mempunyai gelar Abu al-Barakat. Beliau ahli fiqh terkemuka al-Malikiyah yang sangat produktif di bidang tasawuf, fiqh, teologi dll, beliau penganut tarekat Khalwatiyyah yang sangat popular. Imam Ahmad al-Sawi dalam muqaddimah tafsirnya ia mengatakan bahwa tafsir Jalalain ini diterima dari awal hingga akhir sampai kepada pengarangnya. Asal usul sanad al-Sawi (geneologi-nya) dimulai dari al-Sawi sampai al-Mahalli dan alSuyuti. Beliau mengatakan:

${ }^{14}$ Philip K. Hitti, History of The Arabs; Rujukan Induk Dan Paling Otoritatif Tentang Sejarah Peradaban Islam, Terj. R. Cecep Lukman Yasin Dan Dedi Slamet Riyadi (Jakarta: PT Serambi Ilmu Semesta, 2008), 299.

${ }^{15}$ Muhammad Sawi al-Maliki, Hasyiah Al-Sawi 'Ala Tafsir Jalalain, 1:5. 
"Aku telah menerima kitab tafsir ini dari awal hingga akbir dua kali. Dari guruku Syekh Sulaiman al-Jamal dan dari imam Abi al-Barakat al-'Arif Billah, guruku Syekh Ahmad Dardir dari guruku al-'alamah Syekh Amir dan semuanya telah memperoleh dari tajul arifin Syamsuddin Mubammad Salim al-Hafnawi dan dari imam Abi al-Hasan Syekh Ali Sa'idi al-Adawi. Adapun Syekh Hafnawi memperoleh dari Muhammad bin Muhammad al-Badiri al-Dimyati yang dikenal dengan sebutan Ibn al-Mayyit. Ibn al-Mayyit dari Nuruddin Ali Syibramalisi, dari Syekh al-Halabi, dari Ali al-Jburi, dari al-Burhan al-Alqami dari saudaranya Syamsudin Mubammad al-Alqami dari Jalaludin al-Suyuti. Adapun dari jalur alMahalli, al-Halabi memperoleh dari Ziyadi dari Syekh Ramli dari Syekh imam Zakariyya al-Ansari dari al-Mahalli."

Diantara karya-karya intelektual Ahmad Sawi antara lain Balaghatu alSalik li Aqrab al-Masalik fi furu' al-Fiqh al-Maliki, Hasyiah Ala Jauhar al-Tauhid li Alqani, Al-Asrar al-Rabbaniyyah al-Fuyudat al-Rahmaniyyah, Syarh alDardiriyyah, Hasyiah 'ala Tukhfat al-Ikhwan fi 'Ilmi al-Bayan, Hasyiah 'ala Syarh al-Dardir 'Ala Risalatih fî Ilmi al-Bayan, Hasyiat al-Sawi 'ala Syarh alSaghir, Tafsir al-Qur'an al-Karim, Syarh al-Sawi 'alaManzumat al-Dardir fi Asmaillahi al-Husna, Al-Kharidah al-Bahiyyah, Hasyiyat 'alaSyarh al-Dardir 'ala Manzhumatihi, Al-Risalah fi al-Ta'un dan Al-Risalah fî al-Kalam al-Basmalah.

\section{Pandangan Imam Sawi Seputar Isra'iliyyat}

Term secara bahasa, definisi isra'iliyyat berasal dari isim jamak, mufrodnya lafad isra'iliyyah yakni kisah atau cerita yang bersumber dari bani Isra'il. ${ }^{16}$ Kata isra'il adalah bahasa Ibrani yang artinya adalah hamba Allah, berasal dari kata isra'yang artinya hamba atau pilihan dan kata ilun yang maknanya Tuhan. ${ }^{17}$

Isra'iliyyat menurut ulama tafsir dan hadits adalah penafsiran dan kisah umat terdahulu yang bersumber dari kaum yahudi dan nasrani atau lainnya yakni yang sengaja dimasukkan oleh musuh-musuh Islam dalam penafsiran yang dilakukan dengan tujuan untuk merusak akidah Islam. ${ }^{18}$ Ramzi Na'na'ah menyatakan bahwa isra'iliyyat adalah akidah-akidah selain Islam dan kisah-kisah yang sengaja diselipkan dalam akidah Islam baik itu dari yahudi, Nasrani, dan

\footnotetext{
${ }^{16}$ Al-Dzahabi, Al- Isra'illiyat Fi al-Tafsir Wa al-Hadits, 13.

${ }^{17}$ Ramzi Na'na'ah, "Isra'iliyat wa Atsaruha fi kutub al-Tafsir” (Mesir, Darul Qolam, 1970), 72 .

${ }^{18} \mathrm{Al}-\mathrm{Dzahabi,}$ Al- Isra'illiyat Fi al-Tafsir Wa al-Hadits, 14.
} 
agama yang lain. Menurut ahli tahqiq, isra'iliyyat adalah cerita yang sumbernya dari umat yahudi dan nasrani yang disebarkan pada seluruh umat Islam. ${ }^{19}$

Adapun berkaitan dengan permulaan masuknya Isra'iliyyat dalam tafsir al-Qur'an, dapat kita katakan sudah terjadi semenjak zaman sahabat, hal ini dikarenakan terdapatnya persamaan antara al-Qur'an pada satu sisi serta Taurat dan Injil pada sisi lainnya, dimana al-Qur'an dalam pemaparannya bersifat global, sedangkan Taurat dan Injil memaparkan kisah yang sama dengan lebih detail dan rinci. Di samping itu, fenomena merujuk kepada pengetahuan kalangan Abl Kitab merupakan bagian dari sumber penafsiran al-Qur'an bagi sebagian sahabat pada saat itu. ${ }^{20}$

Menurut Fayed Abdul Wahab, ada tiga tahapan yang dilakukan nabi dalam menyikapi riwayat isra'iliyyat ini. Pertama, pelarangan keras dan tegas bagi kaum muslimin untuk membaca, bertanya dan mendengar kabar isra'iliyyat. Di antaranyahadits yang diriwayatkan imam Ahmad, bahwa Umar ibn Khattab menghadap rasul Saw dengan membawa sebuah kitab yang didapat dari ahli kitab. Ketika Umar membacanya dihadapan nabi beliau marah dan berkata, "Apakah engkau ragu tentang isi al-Qur'an wahai Umar? Sunggub aku dating membawanya dalam kondisi putih bersih, janganlah kamu bertanya pada abli kitab karena boleh jadi mereka memberitabu kebenaran tapi kamu mendustakannya, atau memberitabu kebohongan tapi kamu membenarkannya. Demi Drat yang jiwnaku ada ditangan-Nya, seandainya Musa masib bidup pasti tidak ada jalan lain kecuali dia mengikuti ajaranku. ${ }^{21}$

$$
\begin{aligned}
& \text { أن عمر أتى النبي صلى الله عليه وسلم بكتاب أصابه من بعض اهل الكتاب, فقرأه عليه, }
\end{aligned}
$$

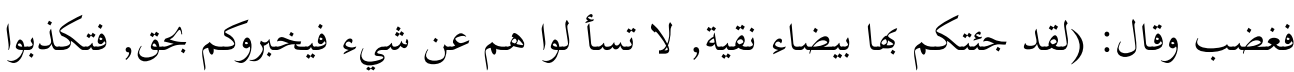

$$
\begin{aligned}
& \text { به, أو ببا طل, فتصدقوا به, والذى نفسى بيده, لو أن موسى حيا ما وسعه الا أن يتبعنى) }
\end{aligned}
$$

Kedua, pemberian izin untuk mendengar riwayat isra'iliyyat dengan syarat tidak membenarkan atau mendustakan riwayat tersebut, tapi cukup mengatakan Kami beriman kepada Allah dan apa-apa yang diturunkan kepada Kami (AlBaqarah: 136). Di antaranya riwayat Bukhari dari Abu Hurairah, diaberkata: "Ketika itu Abli kitab membaca kitab Taurat dengan bahasa Ibrani dan menafsirkannya kepada umat Islam dengan bahasa Arab. Maka rasul bersabda, Janganlab kalian benarkan abli kitab dan jangan pula dustakan mereka tapi katakanlah, Kami beriman kepada Allah dan apa yang diturunkankepada kami”. Sikap ini terjadi di pertengahan dakwah nabi di Madinah di mana pertemuan umat Islam dengan ahli kitab semakin kuat.

${ }^{19} \mathrm{Na}$ 'na'ah, "Isra'iliyat wa Atsaruha fi kutub al-Tafsir" 73.

${ }^{20}$ Yusuf Baihaqi, "Isra’iliyyat Dan Pengaruhnya Terhadap Kitab Kulliyyat Rasa’il Al -Nur Karangan Said Al-Nursi," Jurnal Ijtima’iyya Vol. 9, No. 2 Agustus (2016): 99.

${ }^{21}$ Muhammad Ulinnuha, Metode Kritik. Ad-Dakhil Fi Tafsir; Cara Mendeteksi Adanya Infiltrasi Dan Kontaminasi Dalam Penafsiran Al-Qur'an, 1st ed. (Jakarta: PT Qaf Media Kreativa, 2019), 133. 
Ketiga, pemberian izin untuk berdiskusi, melansir dan meriwayatkan isra'iliyyat dengan syarat riwayat tersebut benar-benar valid dan sesuai ajaran Islam. Diantaranya riwayat imam Bukhari dari Amr bin Ash bahwa Nabi Saw

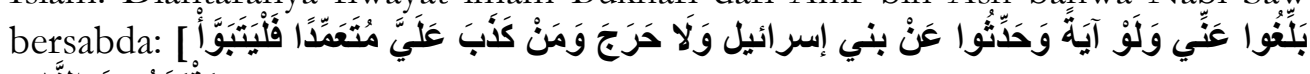
[مَقعَدَهُ مِنَ النَّار cerita bani isra'il karena itu tidaklah mengapa. Barangsiapa sengaja berdusta kepadaku, maka sejatinya ia sedang menyiapkan tempat duduknya di dalam api neraka". Sikap ini terjadi di akhir masa dakwah Nabi di mana umat Islam sudah sangat kuat dan disegani banyak kalangan. ${ }^{22}$

Meskipun terdapat banyak perdebatan tentang benar atau tidaknya kisahkisah dalam al-Qur'an, al-Sawi tetap menghadirkannya ke hadapan umum melalui Hasyiahnya. Akan tetapi, dalam masalah isra'iliyyat atan al-mandhu'at alSawi tidak mencantumkannya kecuali ia telah menghadirkan bukti kebenarannya atau ketidakbenarannya. Sepertihalnya ketika al-Sawi memberi penjelasan dari QS. Al-Baqarah [2]:102 tentang kisah Harut Marut.

"Terkait dengan kisah Harut dan Marut, menurut kisah yang mengakui keberadaannya adalah sesunggubnya ketika para malaikat melibat perbuatan buruk anak. Adam di dunia mereka melapor kepada Allah dan berkata:" Maba suci engkau wahai Tuban kami, engkau telah menciptakan makbluk dan telab engkau muliakan sedangkan ia berbuat maksiat kepadamu. Allah berkata kepada malaikat, jika aku memberikan apa yang telah aku berikan kepada mereka niscaya kalian akan melakukan apa yang mereka lakukan. Para malaikat berkata maha suci engkau kami tidak pernah durbaka kepadamu selamanya. Kemudian Allah berkata, piliblah diantara kalian dua orang malaikat yang paling baik dan paling salih akbimya mereka memilih Harut dan Marut. Kemudian Allah memberi keduanya syabwat dan diperintabkan turun ke bumi dan menghukumi manusia dengan bak, dilarang berbuat syirik, membunuh, zina dan minum khamr. Allah juga mengajari mereka ismul a'dzam yang bisa digunakan untuk naik ke langit pada waktu sore dan turun ke bumi pada waktu pagi". 23

Terdapat perbedaan pendapat tentang kebenaran kisah ini. Imam alHafid ibn Hajar memilih kebenarannya karena ada beberapa riwayat yang datang dari Ahmad bin Hanbal. Tetapi al-Baidawi dan para pengikutnya mengatakan bahwa kisah ini tidak benar. Karena menurutnya, kisah ini tidak datang kecuali dari orang Yahudi.Al-Sawi menghadirkan ringkasan kisah yang ada di balik ayat ini supaya manusia bisa mengambil ibrah, beliau menyebutkan bahwa kisah ini masih khilafiyah terkait kesahihan ceritanya.

${ }^{22}$ Ulinnuha, 134-35.

${ }^{23}$ Muhammad Sawi al-Maliki, Hasyiah Al-Sawi 'Ala Tafsir Jalalain, 1:75. 
Dari contoh isra'iliyyat yang dipaparkan oleh imam al-Sawi, terkadang beliau mengomentari namun terkadang juga tidak. Pada yang tidak ada komentarnya (mendiamkan) bisa menimbulkan keraguan bagi para pembaca misalnya tidak menyertakan persambungan sanadnya dari para rawi isra'iliyyat. Di sini beliau hanya menyandarkan langsung kepada sumber awal riwayat isra'iliyyat sebagaimana kisah Ra'dun wa Barqun yang diperoleh dari imam alAlusi, dari Wahab bin Munabbih. Bahkan ada beberapa riwayat yang sama sekali tidak disertakan sanad-sanadnya seperti kisah postur kaum'Ad yang tidak diketahui asalnya.

Pada dasarnya sikap al-Sawi terhadap riwayat isra'iliyyat sudah ditegaskan dalam muqaddimah tafsirnya yang menyatakan, bahwa beliau tidak menyandarkan riwayat-riwayat tersebut kepada para perawinya, karena baginya, penyandaran kepada penulisnya langsung sudah mencukupi. ${ }^{24}$ Dari pernyataan tersebut menunjukkan bahwa imam al-Sawi tidak perlu menyertakan secara lengkap sanad para periwayat isra'iliyyat, cukuplah disandarkan langsung kepada sumber riwayat. Tanggung jawab yang dimaksud adalah pengakuan al-Sawi bahwa beliau tidak menyandarkan riwayat isra'iliyyat kepada semua sanad. Namun, beliau langsung menyandarkan kepada sumber riwayat isra'iliyyat, dalam menilai kualitas isra'iliyyat. $^{25}$

Imam Sawi mempunyai dua pendapat terhadap kisah isra'iliyyat yaitu pertama, beliau mengomentari riwayat isra'iliyyat dengan menunjukkan mana riwayat yang sahih dan mana yang tidak, al-Sawi tidak hanya mendiamkan begitu saja namun beliau menambah komentar pada tafsirnya sehingga terkesan lebih detail. Kedua, al-Sawi tidak memberikan komentar dan menyandarkan sepenuhnya kepada sumber periwayatannya, baik itu pendapat ulama sebelumnya atau mengikuti pendapat guru-gurunya, namun beliau tetap memberikan penjelasan yang lebih detail tentang kisah yang disampaikan. Beliau tidak bersikap kritis dan selektif terhadap pendapat tersebut, menurut penulis, lebih dikarenakan agar bisa dijadikan ibrah dan renungan, dan juga menunjukkan sikap tawadhu' beliau sebagai seorang shufi yang menganut aliran khalwatiyyah.

.Komentar yang diperlihatkan al-Sawi terhadap riwayat isra'iliyyat belum dikategorikan kritis dan selektif terhadap seluruh riwayat isra'iliyyat, baik kritis dan selektif terhadap matan maupun sanad riwayat tersebut. Penggunaan riwayat isra'iliyyat oleh al-Sawi tanpa disertai sikap kritis dan selektif dikhawatirkan akan menyimpang dari tujuan al-Qur'an yang sesungguhnya. Sebab, sebagaimana yang

${ }^{24}$ Muhammad Sawi al-Maliki, 1:7.

${ }^{25}$ Hakim Mahfud dan Alfian Dhany, "Isra'iliyyat Dalam Kitab Hasyiah Sawi Ala Tafsir Jalalain Karya Ahmad Sawi," Jurnal Studi Ilmu-Imu al-Qur'an Dan Hadis Vol. 19, No. 2 (2018): 183. 
ditandaskan oleh M. Quraish Shihab, kisah-kisah yang bersumber dari Abl alKitab tidak sesuai dengan akal. ${ }^{26}$

Ahmad al-Syirbasi mengatakan bahwa menggunakan riwayat isra'iliyyat harus bertujuan untuk mengurai sejarah lengkap agar menjadi tauladan bagi umat manusia. ${ }^{27}$ Namun jika dilihat dari keadaan serta kualitas imam al-Sawi sebagaimana yang dijelaskan pada biografinya beliau adalah ulama yang menguasai hukum-hukum syari'at, tafsir, fiqh, qira'at serta bahasa. Maka, tidak akan ditemukan kemungkinan penyelewengan penafsiran (ad-dakbil) meskipun tafsirnya bercorak tafsir bil-ra'yi. Karena tafsir beliau termasuk tafsir Ra'yi alMahmudah (Ra'yu yang terpuji). Kredibilitas imam Sawi tidak diragukan lagi sebagai mufassir yang ensiklopedis dengan menguasai berbagai disiplin ilmu. Namun terhadap riwayat isra'iliyyat beliau seperti para pendahulunya mengutip riwayat kurang selektif, riwayatnya ada yang sabih dan maudhu'. Selama tidak berkenaan dengan akidah maka masih diperbolehkan.

Dari situlah kita dapat mengetahui bahwa tujuan beliau memasukkan riwayat isra'iliyyat hanya untuk menjadikan tauladan bagi manusia. Sebab dibalik kisah-kisah dalam al-Qur'an terdapat suri tauladan bagi mereka yang mau berfikir, dan juga tujuan beliau adalah memperkuat dan menunjukkan i'jaz alQur'an bahwa dalam al-Qur'an benar berisi hal yang luar biasa, seperti memperkuat kisah Harut Marut, penjelasan tentang Zainab binti Jahsyi, Kisah Yusuf, kisah nabi Sulaiman dan Ratu Balqis dll yang menunjukkan tentang keberadaannya. Tujuan tersebut sebagaimana standar pokok periwayatan isra'iliyyat yang dikemukakan oleh Muhammad Munir al-Damashqi yakni apabila isra'iliyyat tetap digunakan, hendaknya digunakan sebagai pelengkap (ishtisad) atas kebenaran al-Qur'an semata. ${ }^{28} \mathrm{Hal}$ inilah kiranya yang menjadi landasan al Sawi tetap menampilkan israiliyyat dalam tafsirnya, sebagai pelengkap dari tafsirnya yang luar biasa, yang mensyarahi tafsir jalalain dan yang kajiannya hampir lengkap,semua kajian dibahasnya, baik fiqh, nahwu, sharaf, qira'ah, tasawnf, lughah dll.

\section{Analisis Riwayat Isra'iliyyat dalam Tafsir Hasyiah Al-Sawi}

Penulis akan membahas beberapa riwayat isra'iliyyat yang ada dalam kitab Hasyiyah al-Sawi 'Ala Tafsir Jalalain karya Ahmad bin Muhammad Sawi alMaliki al-Khalwati, seorang ulama asal Mesir lahir tahun 1241 - 1175 H. Penulis

\footnotetext{
${ }^{26}$ Shihab, Membumikan Al-Qur'an; Fungsi Dan Peran Wabyu Dalam Kebidupan Masyarakat, 47.

${ }^{27}$ Mahfud dan Alfian Dhany, "Isra'iliyyat Dalam Kitab Hasyiah Sawi Ala Tafsir Jala>lain Karya Ahmad Sawi," 184.

${ }^{28}$ Rasihon Anwar, Melacak Unsur-Unsur Israiliyat Dalam Tafsir al-Tabari Dan Ibnu Katsir (Bandung: Pustaka Setia, 1999), 51-52.
} 
menemukan ada 12 riwayat isra'iliyyat dalam Tafsir Hasyiah al-Sawi antara lain: Kisah Ismah Anbiya' [QS. Al-A'raf 189-190], Kisah Nabi Yusuf dan Zulaikha [QS. Yusuf: 23-24], Kisah Nabi Ayub [QS. Shad : 42], Kisah Nabi Sulaiman dan Ratu Balqis [QS. An-Naml: 40-44], Kisah Nabi Ibrahim dan putranya yang di sembelih [QS.As-Safat: 100-113], Kisah tentang postur kaum 'Ad [QS. Fusilat: 15, Al-Syu'ara: 128-134], Kaum Bani Israil di padang Tih [QS. Al-Maidah: 2026], Nabi Muhammad dan Zainab binti Jahsyi [QS. Al-Ahzab: 36-37], Kisah Gharaniq [QS. Al-Haj: 52-54], Kisah Harut dan Marut [QS.Al-Baqarah: 102], Isra'iliyyat pembangunan Masjidil Haram dan Hajar Aswad [QS. Al-Baqarah: 127], dan Ra'dun wa Barqun [QS. Al-Baqarah: 19-20,Ar-Ra'du: 12-13]. Namun yang akan dibahas dalam tulisan ini hanya sebagian saja yaitu lima riwayat.

\section{Kisah Ismah Anbiya' [QS. Al-A'raf 189-190]}

Kisah ini bercerita tentang syiriknya Nabi Adam, yang menurut mayoritas ulama tidak mungkin seorang Nabi berbuat syirik, yaitu tatkala nabi Adam telah diturunkan di bumi kemudian diciptakan Hawa sebagai pendamping hidupnya (istrinya), kemudian Adam mencampurinya (j̈ma) sehingga istrinya mengandung. Ketika Hawa hamil tua, keduanya (suami-istri) berdoa memohon kepada Allah Swt agar anak yang dikandung labir dalam keadaan sehat maka mereka akan menjadi hamba yang selalu bersyukur. Namun ketika anak itu telah lahir dalam keadaan sempurna dan sehat, Adam dan Hawa berbuat syirik kepada Allah.

Dalam kisah tersebut al-Sawi menyampaikan riwayat isra'iliyyat yaitu ketika kandungan Hawa sudah tua iblis datang kepadanya dan menakut nakutinya dia berkata, "Wahai Hawa apa yang engkau kandung di perutmu? Hawa menjawab tidak tahu kemudian iblis berkata yang kamu kandung itu sepertinya anjing atau kuda atau mungkin yang lainnya." Selanjutnya Iblis berkata: "Dan kemungkinan itu akan keluar (lahir) dari matamu atau mulutmu atau perutmu akan robek untuk mengeluarkannya." Mendengar ucapan iblis, Hawa menjadi takut dan khawatir dan melaporkannya kepada Adam kemudian nabi Adam berdoa sebagaimana doa di atas. ${ }^{29}$ Kemudian Allah mengabulkannya dan anaknya lahir dengan selamat, nabi Adam lupa dan berbuat syirik yakni dengan memberi namaa naknya Abdul Harits (nama iblis) yang artinya hamba iblis.

Menurut Sawi memberi nama anak Abdul Harits bukan termasuk syirik dalam beragama (ubudiyah) tetapi hanya syirik dalam segi penamaan dan itu tidak mempengaruhi akidah karena seorang nabi adalah ma'sbum terhindar dari hal-hal yang bisa merusak agama. Dalam menafsirkan ayat tersebut Ahmad Sawi menyampaikan sebuah riwayat dari Samurah dengan sanad yang gharib menurut al-Turmudzi bahwasanya Nabi berkata ketika Hawa mengandung dan mau

\footnotetext{
${ }^{29}$ Ahmad bin Muhammad Sawi, Hasyiyah Al-Sawi 'Ala Tafsir Jalalain Mudzillan Bi Lubab alNuqul Fi Asbab al-Nuzul Li Suyuti, vol. 2 (Beirut, Libanon: Darul Fikr, 1993), 138.
} 
melahirkan, iblis berputar-putar mengelilinginya dan sebelumnya Hawa juga mengandung dan anaknya meninggal. Kemudian iblis berkata namailah ia dengan Abdul Harits niscaya ia akan hidup, kemudian Hawa memberikan nama itu dan anaknya hidup maka itu merupakan wahyu setan (bisikannya). Menurut pandangan Sawi, riwayat tersebut tidak bisa dijadikan hujah untuk menentukan syiriknya nabi Adam, bahkan sebagian ulama mengatakan sanadnya tidak bisa diterima. Dalam menafsirkan ayat tersebut, ulama banyak yang terpeleset lidahnya sehingga ada yang membenarkan dan ada yang menyalahkan, padahal dalam beragama kita harus yakin bahwa seorang nabi adalah ma'shum tidak mungkin melakukan hal yang bisa merusak agama. ${ }^{30}$

Menurut Abu Syahbah, menyikapi tafsir di atas dengan merujuk pendapat Ibnu Katsir beliau mengatakan khabar dari ahli kitab dibagi menjadi 3 yakni 1) apa yang kita ketahui kesahihannya berdasarkan al-Kitab dan sunnah;2) apa yang kita ketahui kebohongannya berdasarkan kebalikannya yang ditunjukkan oleh al-Kitab dan sunnah; 3) apa yang didiamkan (tidak ada komentar) inilah yang diizinkan untuk disampaikan berdasarkan sabda nabi "Dan ceritakanlah dari bani isra'il tidak ada dosa.' Ibnu Katsir berkomentar kisah syirik Adam termasuk kategori yang kedua dan masih menjadi perdebatan. ${ }^{31}$

Ibnu Katsir dalam tafsirnya berkomentar, bahwasanya pembahasan pada kedua ayat tersebut terdapat dua pendapat, yaitu: pertama, QS. al-A'raf ayat 189 membahas tentang Adam dan Hawa, ayat 190 membahas tentang anak cucu Adam artinya anak cucu Adam melakukan syirik dengan menjadikan anak yang dianugerahkan sebagai sekutu bagi Allah Swt. kedua, dua ayat tersebut berbicara tentang anak cucu Adam artinya Allah menciptakan kalian dari diri yang satu kemudian dari dirinya diciptakan pasangannya kemudian dianugerahkan anak. Selanjutnya kalian menjadikan syirik atas anak yang telah diberikan dengan lupa dan kufur nikmat. ${ }^{32}$

\section{Kisah Nabi Yusuf dan Zulaikha [QS. Yusuf: 23-24]}

Imam Abi al-Fida' Ismail Ibn Katsir al-Quraisy al-Dimasqy dalam Tafsir al-Qur'an al-Adrim-nya, menjabarkan beberapa pendapat mufassir tentang Surat Yusuf ayat 24: "Sesunggubnya wanita itu telah bermaksud (melakukan perbuatan itu) dengan Yusuf, dan Yusuf pun bermaksud (melakukan pula) dengan wanita itu andaikata Dia tidak melihat tanda (dari) Tuhannya. Demikianlah, agar Kami memalingkan dari

\footnotetext{
${ }^{30}$ Sawi, 2:139.

31 Muhammad Abu Syahbah, Al-Israilliyat wa al-Maudu'at Fi Kitab al-Tafsir (Kairo: Maktabah al-Sunah, 1426), 214-15.

${ }^{32} \mathrm{Ibnu}$ Katsir, Isma'il bin 'Amr al-Quraisy, Tafsir Ibn Katsir (al-Maktabah Syamilah V III), 528
} 
padanya kemungkaran dan kekejian. Sesunggubnya Yusuf itu Termasuk hamba-hamba Kami yang terpilih. Menurutnya ada dua golongan ulama yg berpendapat tentang hal itu yaitu pertama,sependapat dengan ibnu jarir dan lainnya yaitu yang mengatakan bahwa nabi Yusuf berhasrat dan yang kedua sependapat dengan alBaghawi dan mengatakan tidak berhasrat. ${ }^{33}$

Dalam kisah tersebut Ahmad Sawi menjelaskan apa yang telah ditafsirkan dalam tafsir Jalalain tanpa menyebutkan riwayatnya dengan jelas. Beliau mengatakan ketika nabi Yusuf dikurung oleh Zulaikha di dalam kamar bersamanya antara keduanya terdapat rasa saling tertarik untuk berbuat zina baik itu nabi Yusuf sendiri maupun Zulaikha karena menurut penjelasan Sawi hal itu merupakan sesuatu yang sudah lumrah sesuai dengan kodrat manusia, yaitu saling ketertarikan antara perempuan yang sangat cantik dalam satu ruangan dengan pemuda yang gagah dan tampan. Namun yang menghalangi Yusuf untuk berbuat zina adalah petunjuk dari Allah Swt (burbana rabbi). ${ }^{34}$

Menurut Muhammad Abu Syahbah termasuk isra'iliyyat yang dusta dan tidak dibenarkan oleh dalil aqli dan naqli adalah penafsiran seperti di atas sebagaimana komentar beliau terhadap tafsir yang disampaikan oleh Ibnu Jarir, imam Al-Suyuti dalam kitab al-Dur al-Mantsur dan ulama lainnya dalam menafsirkan ayat di atas. Menurutnya penafsiran tentang Hasrat nabi Yusuf telah menyebutkan hal-hal yang bertentangan dengan ismah anbiya' (kesucian para nabi). ${ }^{35}$

Dalam menafsirkan ayat tersbut, al-Sawi juga menjelaskan apakah sebenarnya yang dimaksud dengan lafad burbana rabbi. Menurut beliau ada banyak penafsiran tentang hal itu, antara lain,menurut Ibnu Abbas, nabi Yusuf melihat atap rumah terbelah dan melihat Ya'qub (ayahnya) sedang menggigit jarinya sehingga tidak jadi berbuat zina. Riwayat lain mengatakan Yusuf mendengar suara yang bertanya wahai Yusuf apakah kamu akan berbuat zina dengan wanita itu, sesungguhnya jika kamu tidak berbuat itu kamu akan menjadi seperti burung yang bebas di langit, tidak aka nada yang bisa menguasaimu (memaksa), dan jika kamu berzina dengannya kamu akan seperti burung yang terjatuh di bumi kamu tidak akan bisa berbuat apa-apa. secara garis besar menurut syekh Sawi banyak sekali riwayat yang menjelaskan tentang bentuk petunjuk dari Tuhan ini. ${ }^{36}$

Ibnu Katsir menjelaskan "burhana rabbi" yang dilihat oleh Nabi Yusuf, terdapat banyak cerita dan pendapat, Ibnu Abbas, Mujahid, al-Hasan, Qatadah

${ }^{33} I$ Ibnu Katsir, Isma’il bin 'Amr al-Quraisy, Tafsir Ibn Katsir ( al-Maktabah Syamilah V IV ),

${ }^{34}$ Muhammad Sawi al-Maliki, Hasyiah Al-Sawi 'Ala Tafsir Jalalain, 1:298.

${ }^{35}$ Abu Syahbah, Al-Isra illiyat wa al-Maudu'at Fi Kitab al-Tafsir, 220.

${ }^{36}$ Muhammad Sawi al-Maliki, Hasyiah Al-Sawi 'Ala Tafsir Jalalain, 1:299. 
dan banyak lainnya berkata bahwa Yusuf melihat bayangan ayahnya seakan-akan memandangnya sambil menggigit jarinya. Al-Aufi dan Muhammad Ibn Ishaq berkata bahwa Yusuf melihat bayangan majikannya, suami Zulaikha didepannya saat itu. Ibnu Jarir meriwayatkan dari Muhammad al-Quradhi bahwa Yusuf tatkala melihat keatas pada saat itu melihat tulisan "Janganlah kamu mendekati rina karena itu adalah perbuatan yang keji”. Pendapat-pendapat tersebut tidak ada yang didukung oleh suatu dalil atau hujjah yang meyakinkan. Maka yang benar hendaklah dipahami sebagaimana difirmankan Allah, "Demikianlah Kami memperlihatkan kepadanya (Yusuf) sesuatu tanda yang memalingkannya dari perbuatan keji dan kemungkaran, karena dia adalah termasuk hamba-hamba-Ku yang mukblish, suci dan terpilib ${ }^{37}$ Dari seluruh penjelasan diatas patut kiranya kita mengadopsi pendapat Ibn Katsir, dengan mengikut pendapat Abu Hayan dalam tafsirnya yang di nuqil AS-Sinqiti dalam Adwaul Bayan; pendapat yang rajih mengatakan Nabi Yusuf tidak pernah berhasrat terhadap Zulaikha, karena telah melihat Burbana Robbi (tanda dari Tuhan) ${ }^{38}$

\section{Kisah Nabi Sulaiman dan Ratu Balqis [QS. An Naml: 40-44]}

Dalam kisah ini diceritakan ketika ratu Balqis diundang nabi Sulaiman untuk berkunjung ke istana dan ia memenuhi undangan tersebut. Setelah sampai ke istana, nabi Sulaiman mempersilahkan masuk, namun sebelumnya Sulaiman telah membuat sebuah kejutan untuk ratu Balqis yakni membuat istana yang dihalamannya terdapat kolam yang ditutup dengan kaca (kristal) yang kuat sehingga bisa dilewati. Hal itu dikarenakan ada sebuah riwayat yang mengatakan bahwa kaki ratu Balqis seperti kaki kuda. Kemudian dibangunlah kolam itu sebagai sarana untuk membuktikan riwayat tersebut. Perlu diketahui cerita itu adalah rekayasa (bisikan) dari Jin kemudian nabi Sulaiman memerintahkan Jin untuk membuat kolam itu. Ketika ratu Balqis masuk ke istana dan ingin menghadap nabi Sulaiman, maka ia harus melewati kolam itu. Ratu Balqis mengira kolam itu adalah kolam yang sangat jernih dan banyak ikannya dan ia harus menyeberanginya, jika ingin menghadap langsung nabi Sulaiman. Maka ia menyingkap penutup kakinya dan terlihat betisnya karena mengira itu sebuah kolam, namun ternyata lantai yang dilapisi kaca. Kemudian nabi Sulaiman bisa melihat kaki ratu Balqis dan membuktikan kebenaran riwayat berita tentang kakinya. ${ }^{39}$

${ }^{37}$ Imam Abi al-Fida 'Ismail Ibnu Katsir, Tafsir al-Qur'an al-'Adz̧bim, vol. 3 (Kairo: Dar alQalam Li al-Turas, tt), 120.

${ }^{38}$ Ibnu Katsir, Isma’il bin 'Amr al-Quraisy, Tafsir Ibn Katsir ( al-Maktabah Syamilah V IV), 381

${ }^{39}$ Muhammad Sawi al-Maliki, Hasyiah Al-Sawi 'Ala Tafsir Jalalain, 3:243-244. 
Dalam kisah ini, al-Sawi tidak banyak memberikan komentar beliau hanya menggarisbawahi ketika menjelaskan ayat (وكثفت عن ساقيها ) beliau mengatakan setelah tahu kakinya tersingkap nabi Sulaiman segera memalingkan pandangannya. Sebagian besar ulama menganggap kisah ini termasuk isra'iliyyat demikian juga nabi Sulaiman seorang nabi ingin melihat sesuatu yang diharamkan oleh Allah Swt karena seorang nabi adalah ma'shum. Menurut Abu Syahbah, tafsir yang benar tentang ayat ini adalah keinginan nabi Sulaiman ketika membangun istana dengan tujuan menunjukkan kebesaran kekuasaannya kepada ratu Balqis. Allah memberi kekuasaan kepada nabi Sulaiman yang tidak diberikan kepada ratu Balqis. Seandainya, Balqis tidak melihat agama yang kuat dan akhlak nabi Sulaiman, niscaya ia tidak akan mematuhinya ketika nabi Sulaiman menyeru kepada Allah yang maha Esa dan Maha Haq niscaya ia tidak akan menyesali penyembahan bintang-bintang dan matahari yang dilakukannya sebelumnya serta menyerahkan diri bersama Sulaiman kepada Tuhan semesta alam. ${ }^{40}$

Pendapat Ibn Jarir, al-Tsa'labi, al-Baghawi, al-Khazin menyebutkan bahwa nabi Sulaiman ingin memperistri ratu Balqis, lalu dikatakan kepadanya kakinya seperti kuku keledai dan perempuan yang kedua betisnya berbulu kemudian Balqis masuk istana ia mengira kolam yang besar lalu ia menyingkap kedua betisnya untuk menceburkan diri, Sulaiman melihat Balqis yang memiliki betis yang berbulu, Sulaiman tidak menyukainya dan menyuruh pelayan untuk mencukurnya. Ibnu Katsir menyebut riwayat tersebut diambil dari abli kitab yang terdapat dalam sabifah mereka seperti riwayat Wahab bin Munabih dan Ka'ab alAkhbar. Semoga Allah mengampuni khabar bani isra'il berupa hal mustahil, aneh dan keajaiban yang telah terjadi.

\section{Nabi Muhammad dan Zainab binti Jahsyi, QS. Al-Ahzab: 36-37}

Zainab binti Jahsyiadalah istridari anak angkat Rasulullah Saw yang bernama Zaid bin Haritsah. Zaid sebelumnya adalah seorang budak yang dibeli oleh Khadijah, kemudian diberikan kepada Rasulullah. Dikisahkan Zaid adalah orang yang dikasihi oleh nabi sehingga beliau dijadikan anak angkat oleh nabi Saw kemudian dinikahkan dengan Zainab binti Jahsyi. Sebenarnya Zainab pernah merasa enggan untuk dinikahkan dengan Zaid karena ketika nabi melamarnya, Zainab mengira bahwasanya nabi melamar untuk dirinya sendiri. ${ }^{41}$ Kemudian Zainab menerima lamaran nabi setelah turun ayat:

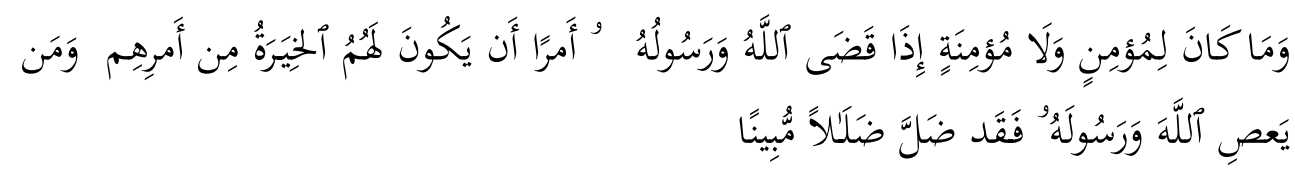

\footnotetext{
${ }^{40} \mathrm{Abu}$ Syahbah, Al-Isra illiyat wa al-Maudu'at Fi Kitab al-Tafsir, 249-250.

${ }^{41}$ Muhammad Sawi al-Maliki, Hasyiah Al-Sawi 'Ala Tafsir Jalalain, 1:343.
} 
'Dan tidaklah patut bagi laki-laki yang mu'min dan tidak. [pula] bagi perempuan yang mu'min, apabila Allah dan Rasul-Nya telah menetapkan suatu ketetapan, akan ada bagi mereka piliban [yang lain] tentang urusan mereka. Dan barangsiapa mendurbakai Allah dan Rasul-Nya maka sunggublah dia telah sesat, sesat yang nyata".

Setelah menikah, seiring berjalannya waktu, Zaid ingin menceraikan Zainab karena ada masalah keluarga. Hal itu diutarakan kepada nabi, namun nabi memberi nasehat agar menahan diri dan mempertahankan pernikahannya, serta bertakwa kepada Allah Swt. Namun pada akhirnya Zaid tetap menceraikan istrinya. Kemudian Allah memerintahkan kepada nabi untuk menikahi Zainab walaupun pada diri nabi ada kekhawatiran akan dicela oleh kaumnya, karena menikahi bekas istri anak angkatnya.

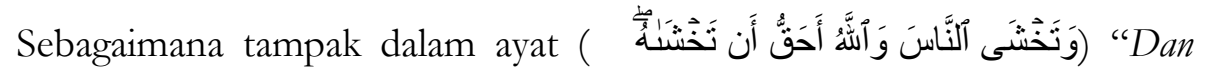
engkau takut kepada manusia dan Allablah yang lebih berbak untuk engkau takuti".

Dalam hasyiah-nya al-Sawi berkata ada sebagian riwayat yang mengatakan maksud ayat di atas adalah nabi menyimpan rasa cinta terhadap Zainab, dan akan dijadikan istrinya ketika Zaid sudah menceraikannya. Namun hal itu tidak tepat dan tidak sesuai dengan derajat kenabian, bahkan tafsir yang demikian adalah salah dan bisa merendahkan derajat nabi yang mulia. Tafsir yang benar tentang ayat di atas adalah sesuatu yang masih dirahasiakan oleh nabi Saw, bahwa Allah telah mewahyukan kepada Nabi, Zainab akan menjadi salah satu istrinya setelah diceraikan oleh Zaid bin Haritsah, hal itu bisa diketahui berdasarkan hadits yang diriwayatkan oleh Ali bin Husain ra. Sesungguhnya rasul Saw telah diberi wahyu bahwa Zainab akan menjadi istrinya (sebelum adanya laporan dari Zaid dimana akan bercerai dengan istrinya) kemudian nabi memberi nasehat agar Zaid mempertahankan istrinya). Hal itulah yang membuat nabi khawatir dan takut dicemooh oleh umatnya namun Allah tetap memerintahkan untuk menikahi Zainab karena banyak hikmah di dalamnya. ${ }^{42}$

Hikmah dibalik kisah ini adalah Islam datang salah satu tujuannya adalah menghilangkan perbedaan-perbedaan antar sesama manusia yang berdiri di atas dasar fanatisme dan semangat jahiliyah karena menurut Islam, semua manusia sama yaitu anak cucu Adam yang membedakan adalah ketakwaannya dan merupakan salah satu tujuannya adalah menghapuskan kebiasaan Arab Jahiliyah, yaitu mengharamkan menikahi istri anak angkat. Hikmah yang lain Allah menghendaki budak pertama yang menikahi gadis Arab murni dari suku Quraisy adalah Zaid bin Haritsah dan pemimpin Arab pertama yang menghapus kebiasaan (haram menikahi istri anak angkat) adalah Rasul Saw. Sampai saat itu, tidak ada seorang pun putri orang terhormat yang menikahi budak. Namun,

\footnotetext{
${ }^{42}$ Muhammad Sawi al-Maliki, 1:344.
} 
Zainab sebagai putri bibi Nabi rela untuk dinikah dan hidup bersama Zaid. Demikian juga belum ada seorang pun pemimpin Arab yang menikahi bekas istri anak angkatnya. Semua itu adalah kehendak Allah.

Sedikit ketakutan dan keraguan nabi Saw terhadap manusia (sehingga beliau menyembunyikan apa yang diberitahu Allah tentang menikahi Zainab, langsung mendapat teguran dari Allah yaitu QS.al-Ahzab: 37. Inilah penafsiran yang sesuai dengan kebenaran dan derajat seorang nabi dan rasul. ${ }^{43}$

\section{Kisah Harut dan Marut [QS. Al-Baqarah: 102]}

Cerita tentang Harut Marut bermacam-macam dan banyak kisah anehdi dalamnya. Ayat yang menjelaskan tentang kisah tersebut dijelaskan al-Qur'an dalam QS.al-Baqarah ayat 102, bersamaan dengan kisah Nabi Sulaiman yaitu kufurnya Nabi Sulaiman atas fitnah keji dari iblis (setan) namun Allah telah mendustakan nabi Sulaiman dan ditegaskan dalam al-Qur'an yaitu potongan ayat

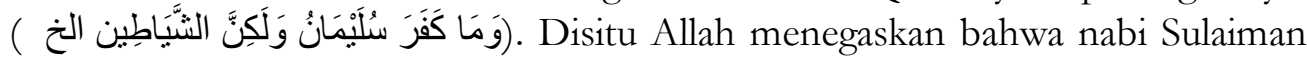
tidak kafir tetapi setan yang berbuat kafir, mereka telah mengajarkan sihir dan memfitnahkannya kepada nabi Sulaiman.

Sedangkan kisah Harut Marut, Ahmad al-Sawi menjelaskan tentang penafsiran dalam Tafsir Jalalain. Beliau menjelaskan bahwa ada beberapa pendapat yang mengatakan Harut dan Marut adalah dua malaikat dan itu bisa diketahui dari riwayat qira'at dengan membaca malakaini dengan membaca fathah lam-nya dan lainnya mengatakan bukan malaikat yaitu riwayat qira'at dengan membaca malikaini dengan membaca kasrah lam-nya adalah bacaan yang syad\%. Berdasarkan bacaan itu, pendapat ini mengatakan keduanya adalah laki-laki yang salih dan dipanggil dengan Harut Marut karena ketampanan dan kesalehannya yang bisa dibandingkan dengan nabi Yusuf sehingga bisa diungkapkan dengan:" Ini adalab bukan manusia tetapi malaikat yang mulia. ${ }^{44}$

Terkait dengan kisah Harut dan Marut, menurut kisah yang mengakui keberadaannya adalah sesungguhnya ketika para malaikat melihat perbuatan buruk anak Adam di dunia mereka melapor kepada Allah dan berkata:" Maha suci engkau wahai Tuhan kami, engkau telah menciptakan makhluk dan telah engkau muliakan sedangkan ia berbuat maksiat kepadamu. Allah berkata kepada malaikat, jika aku memberikan apa yang telah aku berikan kepada mereka niscaya kalian akan melakukan apa yang mereka lakukan. Para malaikat berkata maha suci engkau kami tidak pernah durhaka kepadamu selamanya. Kemudian Allah berkata, pilihlah diantara kalian dua orang malaikat yang paling baik dan paling salih akhirnya mereka memilih Harut dan Marut. Kemudian Allah memberi keduanya syahwat dan diperintahkan turun ke bumi dan menghukumi manusia

\footnotetext{
${ }^{43} \mathrm{Abu}$ Syahbah, Al-Isra'illiyat wa al-Maudu'at Fi Kitab al-Tafsir, 323-324.

${ }^{44}$ Muhammad Sawi al-Maliki, Hasyiah Al-Sawi 'Ala Tafsir Jalalain, 1:74.
} 
dengan hak, dilarang berbuat syirik, membunuh, zina dan minum khamr. Allah juga mengajari mereka ismul a'dz̧am yang bisa digunakan untuk naik ke langit pada waktu sore dan turun ke bumi pada waktu pagi." 45

Kemudian Harut dan Marut didatangi oleh seorang perempuan yang sangat cantik yang bernama Zahrah, mereka jatuh cinta kepadanya dan berusaha untuk merayunya. Perempuan itu mau asalkan kedua orang itu mau melanggar semua larangan yang telah diberikan dan juga mengajarkan ismul a'dzam kepada wanita itu. Akhirnya kedua malaikat itu melanggar apa yang telah dilarang Allah dan mengajarinya asma' al-a'dzam, akhirnya asma' itu digunakan oleh wanita tadi untuk naik ke langit namun Allah telah menghapusnya dan menjadikannya bintang Zahrah yang terkenal. Ketika mengetahui itu kedua malaikat berusaha untuk naik ke langit untuk menghadap Allah menggunakan asma' itu, namun asma' tersebut tidak berfungsi dan mereka tidak bisa terbang. Akhirnya mereka memohon syafa'at kepada nabi Idris as agar berkenan mendoakan mereka dan bisa menghadap Allah.

Selanjutnya mereka bisa menghadap dan Allah memberikan pilihan agar memilih siksa dunia atau siksa akhirat. Mereka memilih siksa dunia, karena mereka tahu bahwa siksa dunia akan habis sedangkan siksa akhirat tidak. Akhirnya sampai saat ini mereka di gantung di Babylonia yaitu dikedua menaranya. Mereka dipukul dengan cambuk yang terbuat dari besi sampai hari kiamat. Matanya berwarna biru dan kulitnya berwarna hitam dan mereka masih tetap mengajarkan sihir kepada manusia.Kedua malaikat diatas juga sangat berhati-hati, mereka tidak mengajarkan sesuatu dari sihir kepada siapapun sebelum memberi peringatan dengan berkata sesungguhnya kami adalah fitnah (bala' dan ujian). Oleh karena itu janganlah kafir dengan mempelajari dan mengamalkannya. Jika niat mempelajarinya hanya untuk mewaspadai maka tidak apa-apa (mubah), tetapi yang diharamkan jika mempelajari ilmu sihir untuk diamalkan.

Ketika rasulullah datang kepada orang Yahudi, mereka mengetahui bahwa beliau adalah nabi yang diberitakan di dalam Taurat sampai mereka memohon kemenangan dalam perang dengan orang musrik dengan menyebut namanya sebelum dia dilahirkan dan diutus.Kemudian ketika datang kepada mereka apa yang mereka ketahui, mereka kufur terhadapnya. Mereka melempar kitab mereka (taurat) danal-Qur'an ke belakang punggung mereka. Mereka bukannya mengikuti kebenaran yang nyata, tapi justru mengikuti sihir yang mereka warisi dari para leluhur dan yang diajarkan setan kepada mereka. Padahal mereka wajib membuang sihir dan memperingatkan manusia terhadap

${ }^{45}$ Muhammad Sawi al-Maliki, 1:75. 
kejahatannya. Sebagaimana yang dilakukan oleh malaikat Harut dan Marut yang memperingatkan manusia dari kejahatan sihir.

Menurut al-Sawi kisahHarut Marut masih terjadi pertentangan terkait kesahihannya, al-Hafidz Ibnu Hajar mengakui kisah itu karena diriwayatkan oleh banyak perawi dari imam Ahmad bin Hanbal sedangkan imam Baidhawi dan pengikutnya menganggap kisah ini tidak ada. Mereka berpendapat riwayat tersebut hanya datang dari orang Yahudi.

Selaras dengan komentar diatas, apa yang disampaikan Ibn Katsir "kisah ini diriwayatkan dari rawi yang banyak sekali dari golongan tabi'in seperti; Mujahid, Al-Sadi, Hasan Al-Bashri, dan lain lain , namun di klaim sebagai hadits marfu' yang palsu adapun jika tidak palsu pasti dari sumber isra'iliyyat, yang diambil dari Ka'ab dan lainnya"

Menurut Abu Syahbah, tafsir yang benar al-Baqarah: ayat 102 "Dan apa yang diturunkan kepada dua malaikat..." jika yang dimaksud dengan apa yang diturunkan adalah ilmu sihir, maka keduanya diturunkan untuk mengajarkannya kepada manusia, agar mereka mewaspadainya. Sebab turunnya dua malaikat untuk mengajari manusia beberapa pintu dari ilmu sihir, agar mereka mengetahui perbedaan antara sihir dan kenabian, sebagaimana Nabi Sulaiman, adalah seorang nabi yang diutus dengan risalah ketuhanan bukan seorang penyihir.Inilah tafsir yang benar bagi ayat ini, bukan tafsir yang diklaim oleh orang yang membuat kebatilan dan khurafat. Dengan demikian terjadi keselarasan antar ayat. Ayat-ayat tersebut menjadi saling berhubungan. Saya tidak tahu apakah hubungan antara isra’iliyyat yang mereka riwayatkan tentang Harut Marut dan firman Allah "padahal keduanya tidak mengajarkan (sesuatu)... selain penafsiran di atas ${ }^{47}$

\section{Kesimpulan}

Dalam menafsirkan isra'iliyyat, imam al-Sawi lebih banyak memberikan keterangan tentang penafsiran suatu ayat secara panjang lebar tanpa memandang apakah riwayat itu sahih, ataupun tidak sahih mengingat kitab Hasyiah al-Sawi merupakan penjabaran dari tafsir Jalalain yang cenderung lebih ringkas.

Setelah menganalisa 12 kajian isra'iliyyat yang bermasalah dalam kitab Hasyiah al-Sawi dapat disimpulkan bahwasanya ada dua sikap yang ditunjukkan Al-Sawiterhadap isra'iliyyat itu, yaitu: 1) Mendiamkannya terdapat dalam 9 kisah; 2) Memberikan komentar dan menunjukkan tentang kisah yang benar terdapat dalam 3 kisah.

\footnotetext{
${ }^{46}$ Ibnu Katsir, Tafsir al-Qur'an al-'Adz̧bim, 3:120.

${ }^{47} \mathrm{Abu}$ Syahbah, Al-Isra 'illiyat wa al-Maudu'at Fi Kitab al-Tafsir, 164-165.
} 


\section{Saran}

Sebagaimana kita ketahui ada tiga pendapat tentang boleh tidaknya meriwayatkan kisah isra'iliyyat. Pertama, riwayat isra'iliyyat yang diketahui kebenarannya karena sesuai ajaran Islam. Kedua, riwayat isra'iliyyat yang diketahui kebohongannya karena bertentangan dengan ajaran agama. Ketiga, riwayat isra'iliyyat yang tidak diketahui status kebenarannya dan kedustaannya karena tidak ada dalil agama yang menegaskan kebenaran/kedustaan riwayat. Boleh jadi, Imam al-Sawi mengutip pendapat ketiga, maka beliau bersikap hatihati (tawaquf) mendiamkan riwayat isra'iliyyat dan menyerahkannya kepada pendapat pembaca. Dari hasil temuan tersebut, diharapkan para pembaca lebih teliti dalam mensikapi kisah isra'iliyyat apalagi jika disampaikan kepada masyarakat. Walaupun kitab ini memback-up tafsir Jalalain yang sudah terkenal, namun terkait isra'iliyyat dalam tafsir apapun hndaknya harus lebih berhati-hati.

Bagi pencinta tafsir, kitab ini sangat direkomendasikan karena pembahasannya sangat komprehensif baik itu ilmu Nahwu, Saraf, Fiqh, Qira'at, tasawuf, dll sangat mencukupi dan juga bahasanya mudah dipahami. Walaupun masih ada kekurangan yaitu tentang isra'iliyyat di mana kebanyakan kitab tafsir juga mengalaminya.

\section{Bibliografi}

Abu Syahbah, Muhammad. Al-Isra illiyat wa al-Maudu'at Fi Kitab al-Tafsir. Kairo: Maktabah al-Sunah, 1426.

Al-Dzahabi, M. Husain. Al- Isra'illiyat Fi al-Tafsir Wa al-Hadits. 3rd ed. Kairo: Maktabah Wahbah, 1986.

. Tafsir Wa Al-Mufassirun. Vol. 1. Beirut, Libanon: Darul Fikr, 1976.

Al-Khafi, Abdul Mun'im. Al-Mausu'ah al-Falsafiyyah. Beirut, Libanon: Dar ibnu Zaidan, tt.

Al-Qattan, Manna' Khalil. Studi Ilmu Al-Qur'an. Pustaka Litera Antarnusa, 2016.

Anwar, Rasihon. Melacak Unsur-Unsur Israiliyat Dalam Tafsir al-Tabari Dan Ibnu Katsir. Bandung: Pustaka Setia, 1999.

Baihaqi, Yusuf. "Isra'iliyyat Dan Pengaruhnya Terhadap Kitab Kulliyyat Rasa'il Al -Nur Karangan Said Al-Nursi." Jurnal Ijtima'iyya Vol. 9, No. 2 Agustus (2016).

Ibnu Katsir, Imam Abi al-Fida 'Ismail. Tafsir al-Qur'an al-'Adæhim. Vol. 3. Kairo:

Dar al-Qalam Li al-Turas, tt.

Jansen, J.J. The Interpretation of The Koran in Modern Egypt. Leiden: E.J. Brill, 1984. 
K. Hitti, Philip. History of The Arabs; Rujukan Induk Dan Paling Otoritatif Tentang Sejarah Peradaban Islam, Terj. R. Cecep Lukman Yasin Dan Dedi Slamet Riyadi. Jakarta: PT Serambi Ilmu Semesta, 2008.

Mahfud dan Alfian Dhany, Hakim. "Isra'iliyyat Dalam Kitab Hasyiah Sawi Ala Tafsir Jalalain Karya Ahmad Sawi." Jurnal Studi Ilmu-Imu al-Qur'an Dan Hadis Vol. 19, No. 2 (2018).

Muhammad Sawi al-Maliki, Ahmad. Hasyiah Al-Sawi 'Ala Tafsir Jalalain. Vol. 1. Beirut, Libanon: Darul Fikr, 1993.

Muhammad Ya'qub, Tahir Mahmud. Asbab Al-Khata' Fi al-Tafsir. Riyad, Arab Saudi: Dar Ibn al-Jauzī, 1425.

Na'na'ah, Ramzi. "Isra'iliyat wa Atsaruha fi kutub al-Tafsir." Darul Qolam, 1970.

Nuwaihid, Adil. Mu'jam al-Mufassirin min Sadr al-Islam Hatta Al-'Asri al-Hadir. 2nd ed. Vol. 1. Libanon: Muasasah Nuwaihid al-Tsaqafiyah li al-Ta'lif wa alTarmah wa al-Nasyr, 1986.

Sawi, Ahmad bin Muhammad. Hasyiyah Al-Sawi 'Ala Tafsir Jalalain Mudrillan Bi Lubab al-Nuqul Fi Asbab al-Nuzul Li Suyuti. Vol. 2. Beirut, Libanon: Darul Fikr, 1993.

Shihab, M. Quraish. Membumikan Al-Qur'an; Fungsi Dan Peran Wabyu Dalam Kehidupan Masyarakat,. Bandung: Mizan, 1998.

Shofa, Maryam. "Ad-Dakhil Dalam Tafsir Al-Jami‘ Li Ahkam Al-Qur'Ān Karya al-Qurtubī: Analisis Tafsir Surah al-Baqarah.” Subuf Vol. 6, No. 2 (2013).

Syahbah, Muhammad Abu. Al-IsraTlliyat Dan Hadits-Hadits Palsu Tafsir al-Qur'an, Terj. Mujabidin Mubayan Dkk. 2nd ed. Depok: Keira Publising, 2016.

Syaltut, Muhammad. Fatwa-Fatwa Terj. Busamin A. Ghani. Vol. 1. Jakarta: Bulan Bintang, 1977.

Ulinnuha, Muhammad. Metode Kritik Ad-Dakbil Fi Tafsir; Cara Mendeteksi Adanya Infiltrasi Dan Kontaminasi Dalam Penafsiran Al-Qur'an. 1st ed. Jakarta: PT Qaf Media Kreativa, 2019. 